\title{
Intracranial Bleeding during Treatment with Sorafenib for Hepatocellular Carcinoma
}

\author{
Taigo Hata Tadashi Uwagawa Katsuhiko Yanaga \\ Department of Surgery, Jikei University School of Medicine, Tokyo, Japan
}

A 75-year-old man with non-B, non-C hepatocellular carcinoma (HCC) underwent central bisegmentectomy of the liver in 2010 (UICC 7th Classification Stage III). He developed recurrent HCC 14 months later, for which he underwent partial liver resection. In 2014, sorafenib was started for lung metastasis. He had no known risk of cerebral hemorrhage including anticoagulation. Four days after starting sorafenib, he developed extensive cerebral hemorrhage (Fig. 1), for which emergency craniotomy was performed. Pathological diagnosis was metastatic HCC, and the bleeding was judged due to metastatic HCC.

According to the 19th National Primary Liver Cancer Follow-Up Survey Report of the Liver Cancer Study Group of Japan, brain metastasis was the initial presenting feature in 0.098\% [1]. In the Nexavar information, an increased risk of bleeding may occur following sorafenib administration. But in the HCC study, an excess of bleeding was not apparent (http://labeling.bayerhealthcare.com/html/products/pi/Nexavar_PI.pdf). Kim et al. [2] reported that chemotherapy was not a significant risk factor for post-radiation treatment intracranial hemorrhage of brain metastases from HCC. For renal cell carcinoma, Stadler et al. [3] reported 1,891 patients given sorafenib treatment, including 70 patients with brain metastasis, for whom no intracranial hemorrhage was documented. Even for anti-vascular endothelial growth factor drugs other than sorafenib for HCC, there has been no report of an increased risk of brain hemorrhage, regardless of the status of brain metastasis [4]. Furthermore, a clinical trial with sorafenib for brain metastases from various types of cancer has been reported [5]. According to the prescribing information, Nexavar is not contraindicated in patients with brain metastasis. Though the causal relationship between brain hemorrhage and metastatic brain tumor is unknown, the following two issues are to be clarified: Firstly, is routine evaluation of the central nervous system required prior to starting sorafenib treatment? Secondly, can sorafenib be a treatment option for patients with brain metastases? Presently, central nervous system screening for brain metastasis of HCC is not a prerequisite for sorafenib treatment. Some patients with HCC who developed cerebral hemorrhage may have bled from brain metastasis of HCC. The same issue might apply to novel multi-kinase inhibitors such as regorafenib or lenvatinib. More data need to be collected rather urgently to estimate the incidence of hemorrhage from brain metastasis of HCC during sorafenib treatment. 


\begin{tabular}{l|l}
\hline DOI: 10.1159/000496546 & $\begin{array}{l}\text { @ 2019 S. Karger AG, Basel } \\
\text { www.karger.com/lic }\end{array}$ \\
\hline
\end{tabular}

Hata et al.: Intracranial Bleeding during Treatment with Sorafenib for HCC

Fig. 1. Head CT scan (4 days after starting sorafenib treatment): extensive brain hemorrhage was seen in the left frontal cortex (arrow).

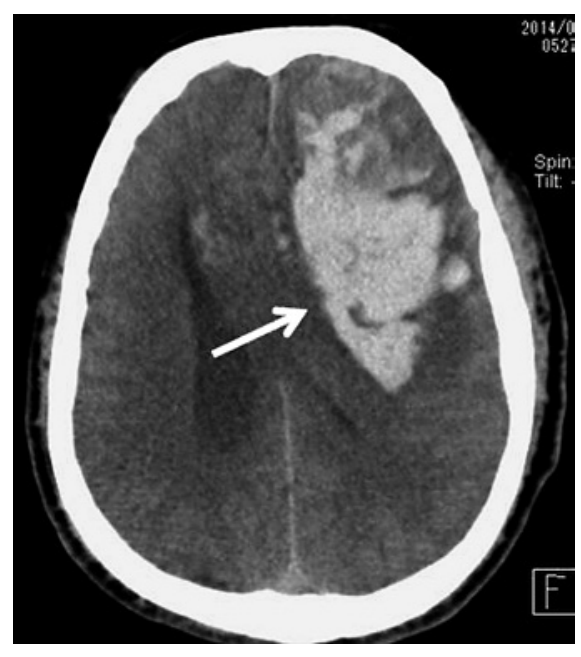

\section{Disclosure Statement}

Taigo Hata and Tadashi Uwagawa have no conflict of interest. Katsuhiko Yanaga received research funding from Takeda Pharmaceutical Company, Covidien Japan, Chugai Pharmaceutical Co., Ltd., Pfizer Japan Inc., and Toyama Chemical Co., Ltd.

\section{Funding Sources}

The authors have no funding sources.

\section{References}

1 Kudo M, Izumi N, Ichida T, Ku Y, Kokudo N, Sakamoto M, et al. Report of the 19th follow-up survey of primary liver cancer in Japan. Hepatol Res. 2016 Mar;46(5):372-90.

2 Kim KS, Kim K, Chie EK, Kim YJ, Yoon JH, Lee HS, et al. Post-treatment intracranial hemorrhage of brain metastases from hepatocellular carcinoma. Radiat Oncol J. 2015 Mar;33(1):36-41.

3 Stadler WM, Figlin RA, McDermott DF, Dutcher JP, Knox JJ, Miller WH Jr, et al.; ARCCS Study Investigators. Safety and efficacy results of the advanced renal cell carcinoma sorafenib expanded access program in North America. Cancer. 2010 Mar;116(5):1272-80.

4 Carden CP, Larkin JM, Rosenthal MA. What is the risk of intracranial bleeding during anti-VEGF therapy? Neuro-oncol. 2008 Aug;10(4):624-30.

5 Arneson K, Mondschein J, Stavas M, Cmelak AJ, Attia A, Horn L, et al. A phase I trial of concurrent sorafenib and stereotactic radiosurgery for patients with brain metastases. J Neurooncol. 2017 Jun;133(2):435-42. 